\title{
Differences in Anthropometric Characteristics among Junior Soccer and Handball Players
}

\author{
Fitim Arifi', Dusko Bjelica² and Bojan Masanovic ${ }^{2}$ \\ ${ }^{1}$ Institute of Sports Anthropology, Prishtina, Kosovo, ${ }^{2}$ University of Montenegro, Faculty for Sport and Physical Education, Niksic, Montenegro
}

\begin{abstract}
The aim of this study was to obtain the relevant knowledge about significant differences in some anthropometric characteristics of junior soccer and handball players. The sample included 40 male subjects divided into two subsamples. The first subsample included 25 subjects, who train in the junior selection in the Football club Vojvodina from Novi Sad, while the other subsample included 15 subjects who train in the junior selection in the Handball club Vrbas, from Vrbas. The variables sample included 20 anthropometric measures that defined longitudinal and transversal dimensionality of skeleton, volume and mass of the body, and subcutaneous adipose tissue. The results is analysed in a statistical procedure marked as a significance testing of two arithmetic means of the independent samples, a t-test at the level of significance of $p<0.05$. Based on the result, it was concluded that significant differences occur in wrist diameter, ankle joint diameter, upper arm circumference (min), upper arm circumference (max), lower leg circumference (max), upper arm skinfolf, lower arm skinfold, thigh skinfold, calf skinfold, chest skinfold and abdomen skinfold, while the significant difference does not occur in body height, bodyweight, elbow diameter, knee diameter, lower arm circumference (min), lower arm circumference (max), upper leg circumference (min), upper leg circumference (max), and lower leg circumference (min).
\end{abstract}

Key words: anthropometric measurement, different sports, junior league

\section{Introduction}

Athletes, competing in different sports and sports disciplines, differ in their physical and physiological characteristics (Stojanovic et al., 2016; Morteza Tayebi, Mahmoudi, Shirazi, \& Sangi, 2017). All competitive sports practiced at a higher level require that the body performs at the optimal biomechanical and physiological capacity (Saavedra et al., 2018). Logically, a junior athlete competing in the strongest leagues in his age group is expected to have the optimal physique, strength, and endurance for the functional requirements of the sport in question (Masanovic, 2018a). Morphological characteristics are of great importance when it comes to orientation and selection in all sports disciplines since they are present in the equation of the specification of almost every sport (Nikolaidis \& Vassilios-Karydis, 2011; Gjonbalaj, Georgiev, \& Bjelica, 2018 ). The coefficients of participation of some morphological dimensions in the equation of the specification a particular sport are constantly changing, primarily due to the development of technique and tactics, therefore for effective identification of talents, the continuous participation of sports science and practice is required (Popovic, Bjelica, Jaksic, \& Hadzic, 2014).

Body mass can affect the speed, durability and physical dominance of athletes, while the composition of the body inevitably affects the strength and agility, and for the successful handling of football and handball, each individual requires a high level of athletic abilities and appropriate atropometric characteristics and body composition, beside high level of technical and tactical skills (Popovic, Akpinar, Jaksic, Matic, \& Bjelica, 2013).

Soccer is a team sport which is played on an open field of great dimensions, and therefore requires a high standard of physical preparation, it is also based on a large number of movements, and a series of moderate activities that periodically replace high intensity activities, leading to significant

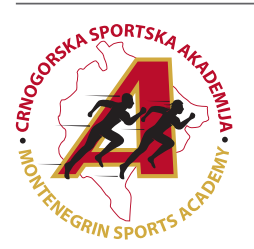

Correspondence:

B. Masanovic

University of Montenegro, Faculty for Sport and Physical Education, Niksic, Montenegro

E-mail: bojanma@ucg.ac.me 
metabolic heat production, and an intensity of $75-90 \%$ of the maximum heart rate, or $70-80 \%$ of the maximum oxygen consumption (Rexhepi \& Brestovci, 2010; Sæther, 2017; Amani, Sadeghi, \& Afsharnezhad, 2018). On the other hand, handball is played in the field of smaller dimensions, however, it is considered as one of the fastest team sports and also requires great durability and strength due to constant contact with the opponent's body and specific maneuvers such as jumping, pressurizing, blocking and shooting on goal (Bilge, 2013; Masanovic, Milosevic, \& Corluka, 2018).

The aim of this research is to describe the morphological profile of young soccer and handball players, to determine if there is a difference in anthropometric dimensions between them, and to define its scale.

\section{Methods}

The sample included 40 male subjects divided into two subsamples. The first subsample included 25 soccer players $(16.64 \pm 0.49 \mathrm{yrs})$, who trained in the junior selection in the Soccer club "Vojvodina" from Novi Sad, which competed in Serbian Junior League, while the other subsample included 15 handball players $(16.93 \pm 0.59 \mathrm{yrs})$, who trained in the junior selection in the Handball club "Vrbas" from Vrbas, which also competed also in Serbian Junior League. Criteria for selection of subjects for the sample were as follows: they have been members of the first team squad for at least one year and that they are in good health.

Anthropometric research technique is used for data collection. A total of 20 anthropometric measures were evaluated, that defined the longitudinal and transversal dimensionality of skeleton, body volume and body mass, and subcutaneous adipose tissue: body height, body weight, elbow diameter, wrist diameter, knee diameter, ankle joint diameter, minimum circumference of the upper arm, maximum circumference of the upper arm, minimum circumference of the forearm, maximum circumference of the forearm, minimum circumference of the upper leg, maximum circumference of the upper leg, minimum circumference of the lower leg, maximum circumference of the lower leg, skinfold thickness of the upper arm, skinfold thickness of the forearm, skinfold thickness of the thigh, skinfold thickness of the calf, skinfold thickness of the chest and skinfold thickness of the abdomen.

Anthropometric research was conducted according to IBP standards, while respecting the basic rules and principles related to the selection of parameters, standard conditions and measuring techniques, as well as the standard measuring instruments calibrated before measuring.

The measuring was carried out in the middle of the competitive season. The data obtained in the research were analyzed with the statistical program SPSS 20.0, adapted for use on personal computers. The arithmetic mean, standard deviation and standard errors of the arithmetic mean of the anthropometric characteristics were calculated for respondents who are professional soccer players and professional handball players, by testing the differences of arithmetic means of independent samples at a significance level of $\mathrm{p}<0.05$. This analysis gave answer to the question whether there is a difference, and the scope of it, between the anthropometric characteristics of the soccer and handball players, regulars who compete in union divisions.

\section{Results}

This section presents the results of central tendency and dispersion parameters, as well as the results of $t$-test for independent samples, classified into tables. Observing the results of the central tendency and dispersion parameters of longithudinal and transversal skeletal dimensionality, body volume and body mass of the soccer and handball players, we immediately notice that handball players have higher value in 18 variables, while soccer players have higher values in only 2 parameters (Table 1).

Table 1. Descriptive Statistics of Anthropometric Measures

\begin{tabular}{|c|c|c|}
\hline & $\begin{array}{c}\text { Soccer } \mathbf{N}=\mathbf{2 5} \\
\mathrm{AM} \pm \mathrm{SD}\end{array}$ & $\begin{array}{c}\text { Handball } \mathrm{N}=15 \\
\mathrm{AM} \pm \mathrm{SD}\end{array}$ \\
\hline Body height (cm) & $177.80 \pm 6.63$ & $181.51 \pm 5.33$ \\
\hline Bodyweight (kg) & $69.90 \pm 6.78$ & $74.73 \pm 10.17$ \\
\hline Elbow diameter (mm) & $70.60 \pm 3.17$ & $69.95 \pm 4.32$ \\
\hline Wrist diameter (mm) & $55.67 \pm 2.87$ & $59.96 \pm 6.21$ \\
\hline Knee diameter (mm) & $99.74 \pm 4.02$ & $101.17 \pm 7.36$ \\
\hline Ankle joint diameter (mm) & $72.20 \pm 2.25$ & $76.48 \pm 6.21$ \\
\hline Upper arm circumference (min) (cm) & $27.62 \pm 1.90$ & $29.17 \pm 2.81$ \\
\hline Upper arm circumference (max) (cm) & $29.54 \pm 2.12$ & $31.47 \pm 2.92$ \\
\hline Lower arm circumference (min) (cm) & $16.96 \pm 0.84$ & $17.10 \pm 1.17$ \\
\hline Lower arm circumference (max) $(\mathrm{cm})$ & $24.84 \pm 1.18$ & $25.83 \pm 2.03$ \\
\hline Upper leg circumference (min) (cm) & $39.80 \pm 2.38$ & $40.27 \pm 3.54$ \\
\hline Upper leg circumference (max) (cm) & $54.04 \pm 3.63$ & $56.53 \pm 5.63$ \\
\hline Lower leg circumference (min) (cm) & $23.64 \pm 1.04$ & $23.60 \pm 1.45$ \\
\hline Lower leg circumference (max) (cm) & $35.46 \pm 1.81$ & $37.77 \pm 2.86$ \\
\hline Upper arm skinfolf (mm) & $4.82 \pm 1.29$ & $6.20 \pm 1.22$ \\
\hline Lower arm skinfold (mm) & $5.65 \pm 1.65$ & $6.77 \pm 1.70$ \\
\hline Thigh skinfold (mm) & $9.40 \pm 3.23$ & $14.40 \pm 4.27$ \\
\hline Calf skinfold (mm) & $8.10 \pm 2.32$ & $11.60 \pm 2.87$ \\
\hline Chest skinfold (mm) & $7.18 \pm 1.92$ & $9.60 \pm 3.46$ \\
\hline Abdomen skinfold (mm) & $6.82 \pm 1.99$ & $9.59 \pm 4.03$ \\
\hline
\end{tabular}

Legend: $\mathrm{N}$ - number of Subjects, AM - arithmetic mean, $\mathrm{S}$ - standard deviation 
On the basis of the results presented it was determined that the subsamples are significantly different in 11 out of 20 anthropometric characteristics (level of significance $\mathrm{p}<0.05$ ). Based on results, it was concluded that significant differences occur in wrist diameter, ankle joint diameter, upper arm circumference (min), upper arm circumference (max), lower leg circumference $(\max )$, upper arm skinfolf, lower arm skinfold, thigh skinfold, calf skinfold, chest skinfold and abdomen skin- fold, while the significant difference does not occur in body height, bodyweight, elbow diameter, knee diameter, lower arm circumference $(\min )$, lower arm circumference $(\max )$, upper leg circumference (min), upper leg circumference (max), and lower leg circumference (min). For each of the parameters in which a significant difference has been found, higher values can be seen in handball players (Table 2).

Table 2. Independent Samples t-test

\begin{tabular}{lcccccccc}
\hline & F & T & Df & P & MD & SED & Min & Max \\
\hline Body height & .20 & -1.83 & 38 & .075 & -3.71 & 2.02 & -7.80 & 0.39 \\
Bodyweight & 3.19 & -1.81 & 38 & .079 & -4.83 & 2.68 & -10.25 & 0.59 \\
Elbow diameter & .65 & .55 & 38 & .585 & 0.65 & 1.19 & -1.75 & 3.06 \\
Wrist diameter & 4.80 & -2.98 & 38 & .005 & -4.29 & 1.44 & -7.20 & -1.37 \\
Knee diameter & 9.24 & -0.80 & 38 & .430 & -1.43 & 1.79 & -5.06 & 2.20 \\
Ankle joint diameter & 3.04 & -3.14 & 38 & .003 & -4.28 & 1.36 & -7.04 & -1.52 \\
Upper arm circumference (min) & 6.14 & -2.08 & 38 & .045 & -1.55 & 0.74 & -3.05 & -0.04 \\
Upper arm circumference (max) & 2.53 & -2.41 & 38 & .021 & -1.93 & 0.80 & -3.54 & -0.31 \\
Lower arm circumference (min) & 2.39 & -.44 & 38 & .662 & -0.14 & 0.32 & -0.78 & 0.50 \\
Lower arm circumference (max) & 9.94 & -1.96 & 38 & .057 & -0.99 & 0.51 & -2.02 & 0.03 \\
Upper leg circumference (min) & 4.48 & -.50 & 38 & .620 & -0.47 & 0.93 & -2.36 & 1.43 \\
Upper leg circumference (max) & 5.77 & -1.71 & 38 & .096 & -2.49 & 1.46 & -5.45 & 0.47 \\
Lower leg circumference (min) & 2.51 & .10 & 38 & .920 & 0.04 & 0.39 & -0.76 & 0.84 \\
Lower leg circumference (max) & 7.03 & -3.14 & 38 & .003 & -2.31 & 0.73 & -3.79 & -0.82 \\
Upper arm skinfolf & .12 & -3.33 & 38 & .002 & -1.38 & 0.41 & -2.22 & -0.54 \\
Lower arm skinfold & .82 & -2.07 & 38 & .045 & -1.13 & 0.54 & -2.23 & -0.02 \\
Thigh skinfold & 2.50 & -4.20 & 38 & .000 & -5.00 & 1.19 & -7.41 & -2.59 \\
Calf skinfold & .05 & -4.22 & 38 & .000 & -3.50 & 0.83 & -5.18 & -1.82 \\
Chest skinfold & 12.23 & -2.86 & 38 & .007 & -2.42 & 0.85 & -4.14 & -0.71 \\
Abdomen skinfold & 9.41 & -2.91 & 38 & .006 & -2.77 & 0.95 & -4.70 & -0.85 \\
\hline
\end{tabular}

Legend: $F$-value of Levene's test of equality of variances, $t$-value of $t$-test, df-number of degreeseof freedom, $p$-significance of twotailed testing of arithmetic mean difference, MD-arithmetic mean difference, SED-standard error of diffeence, Min-the level of lower difference interval, Max-level of

\section{Discussion}

On the basis of the data obtained in this study, it was found that there are significant differences in certain anthropometric characteristics between soccer players and handball players who compete in the best junior leagues in Serbia. When it comes to longitudinal dimensionality, significant differences have not been found at body height, which is not supported by previous research (Taborsky, 2007; Popovic, Bjelica, Petkovic, \& Muratovic, 2012). The body height of handball players obtained by this study raises doubt that the selection process has been carried out correctly especially due to the fact that official statistical data proved that Serbian handball players are shorter than the most successful teams which participated in the IHF Men's Youth World Championship played in Russia 2015. For example, the average body height of the players of the French National team, the winning team, was 191.8 centimeters, while the 13 th Korea had an average of 183.4 centimeters and 19th Poland had an average 190.1 centimeters. This insight may suggest the coaches from Serbia to follow the recent selection process methods and to be more careful during the talent identification as they have a very tall population in general (Bjelica et al., 2012; Milasinovic, Popovic, Matic, Gardasevic, \& Bjelica, 2016; Popovic, 2017; Masanovic, 2018b). The absence of a significant body mass difference is also a surprise, as the previous literature indicates a significantly higher body weight of the handball players (Sedeaud et al., 2014), which again points to gaps in the selection of the examined group of players.

Results related to measures of the skeleton transversal and body volume showed significantly higher values for handball players. Subcutaneous adipose tissue showed significantly higher values for handball players for all 6 variables (upper arm skinfolf, lower arm skinfold, thigh skinfold, calf skinfold, chest skinfold, abdomen skinfold). These results are in line with previous research (Muratovic, Vujovic, \& Hadzic, 2014; Gusic, Popovic, Molnar, Masanovic, \& Radakovic, 2017; Vukotic, Corluka, Vasiljevic, \& Bubanja, 2018) which is also logical because in research, soccer is recognized as an aerobic sport in which activity lasts longer and running distance is greater (Popovic et al., 2013; Popovic, Masanovic, Molnar, \& Smajic, 2009; Gardasevic, Bjelica, \& Popovic, 2015). On the other hand, handball is played on a smaller pitch, the running distance during the match is less which justifies somewhat higher value of the thickness of the skin folds. Considering the movement patterns in handball, bigger diameters of hand wrist diameter and ankle joint diameter, and higher values of upper arm circumference ( $\max$ ) and lower arm circumference ( $\mathrm{min})$, are expected primarily for the reason that handball is a sport that requires a lot of power, constant contact with hands and body with an opponent, as well as specific maneuvers such as shooting, blocking and jumping, and the strength of the arm, shoulder band and ankle joint gives advantage 
in defense and attack because players who have that ability can gain easier an advantage in the mentioned elements of the game (Vila Suarez, Ferragut, Alcaraz, Rodriguez Suarez, \& Cruz Martinez, 2008; Masanovic et al., 2018).

Being a professional athlete requires a high level of preparation which, in addition to motor and functional abilities, must be supported by morphological characteristics that should correspond, through the perfect harmony, based on sport structure, to the rank of the competition and the specifics of the player position, which differ within almost every sport branch (Vukasevic, Spaic, Masanovic, 2018).

The aim of this research was to determine whether there is a difference, and the scope of it, in anthropometric characteristics between the junior soccer and handball players, and to characterize, as acurately as possible, the morphological characteristics of subjects by measuring the individual body parts.

Considering the movement patterns in handball, slightly greater body height and body mass, are expected primarily for the reason that handball is a sport in which body height gives advantage in defence and attack because taller players have the ability to easily shot through the opponent's defense and set a strong defensive goal in front of their goal through which opposing attackers have less chance of hitting (Muratovic et al., 2014; Gusic et al., 2017), while bigger diameters of the most joints, and higher values of al extremities' circumferences are expected because these features allow players to gain an advantage during the performance of defensive elements that contain the grit and capture, and also give an edge in the performance of the shot that is the most important element of the game (Popovic et al., 2014). Movement patterns in soccer are the reason for lower subcutaneous adipose tissue values for soccer players because in research, soccer is recognized as an aerobic sport in which activity lasts longer and running distance is greater (Popovic et al., 2013). On the other hand, handball is played on a smaller pitch, the running distance during the match is shorter, and the players on certain positions are capable (thanks to their heawier) topush out the opponent and get better position for a shot (Massuca \& Fragoso, 2011), which justifies somewhat higher value of the thickness of the skin folds. However, smallest difference is the seen in the arm skinfolf variables and bigger in the thigh an abdomen skinfold. The reason for that can be found in the fact that handbal players use both upper and lower extremities during the game, which is not the case in soccer.

Morphological characteristics of topclass soccer and handball players appear to be of great interest for some authors (Krespi, Sporis, \& Popovic, 2019; Barraza et al., 2015) with the interest of finding the best morphology somatotype for particular sports, competition levels and player positions as well. Comparison of anthropometrics should support coaches with better understanding of specific demands of certain sport, where particular morphology profile of athlete, combined with motor and functional abilities, should express its full potential (Gusic et al. 2017).

\section{Acknowledgements}

There are no acknowledgements.

\section{Conflict of Interest}

The authors declare that there are no conflicts of interest.

Received: 15 August 2018 | Accepted: 05 October 2018 | Published: 01 February 2019

\section{References}

Amani, A.R., Sadeghi, H., \& Afsharnezhad, T. (2018). Interval training with blood flow restriction on aerobic performance among young soccer players at transition phase. Montenegrin Journal of Sports Science and Medicine, 7(2), 5-10. doi: 10.26773/mjssm.180901

Barraza, F., Yanez, R., Tuesta, M., Nunez, P., Zamora., Y, \& Rosales, G. (2015). Perfil Antropométrico por Posicion de Juego en Handbolistas Chilenos. International Journal of Morphology, 33(3), 1093-1101. doi: 10.4067/ S0717-95022015000300045

Bilge, M. (2013). Interval Training Specific to Handball and Training Programme Designs. World Applied Sciences Journal, 25(7), 1066-1077.

Bjelica, D., Popovic, S., Kezunovic, M., Petkovic, J., Jurak, G., \& Grasgruber, P. (2012). Body Height and Its Estimation Utilizing Arm Span Measurements in Montenegrin Adults. Anthropological Noteboos, 18(2), 69-83.

Gardasevic, J., Bjelica, D., \& Popovic, S. (2015). The effects of the training in the preparation period on the agility transformation with cadet level football players. Sport Mont, 13(43-44-45), 355-60.

Gjonbalaj, M., Georgiev, G., \& Bjelica, D. (2018). Differences in Anthropometric Characteristics, Somatotype Components, and Functional Abilities among Young Elite Kosovo Soccer Players Based on Team Position. Int. J. Morphol., 36(1), 41-7.

Gusic, M., Popovic, S., Molnar, S., Masanovic, B., \& Radakovic, M. (2017). Sport-Specific Morphology Profile: Differences in Anthropometric Characteristics among Elite Soccer and Handball Players. Sport Mont, 15(1), 3-6.

Krespi, M., Sporis, G., \& Popovic, S. (2019). Exponential versus linear tapering in junior elite soccer players: effects on physical match performance according to playing positions. Montenegrin Journal of Sports Science and Medicine, 8(1), Ahead of Print. doi: 10.26773/mjssm.190303

Masanovic, B. (2018a). Comparative study of anthropometric measurement and body composition between junior basketball and volleyball players from Serbian national league. Sport Mont, 16(3), 19-24. doi: 10.26773/ smj.181004

Masanovic, B. (2018b). Standing height and its estimation utilizing arm spam and foot length measurements in dinaric alps population: a systematic review. Sport Mont, 16(2), 101-106. doi: 10.26773/smj.180619

Masanovic, B., Milosevic, Z., \& Corluka, M. (2018). Comparative Study of Anthropometric Measurement and Body Composition between Junior Handball and Volleyball Players from Serbian National League. International Journal of Applied Exercise Physiology, 7(4), 1-6. doi: 10.30472/ ijaep.v7i4.313

Massuca, L. \& Fragoso, I. (2011). Study of Portuguese handball players of different playing status. A morphological and biosocial perspective. Biology of Sport, 28(1), 37-44.

Milasinovic, R., Popovic, S., Matic, R., Gardasevic, J., \& Bjelica, D. (2016). Body Height and its Estimation Utilizing Arm Span Measurements in Male Adolescents from Southern Region in Montenegro. Sport Mont, 14(2), 21-23.

Morteza Tayebi, S., Mahmoudi, A., Shirazi, E., \& Sangi, M. (2017). Acute Response of Some Iron Indices of Young Elite Wrestlers to Three Types of Aerobic, Anaerobic, and Wrestling Exercise. Montenegrin Journal of Sports Science and Medicine, 6(1), 5-11.

Muratovic, A., Vujovic, D., \& Hadzic, R. (2014). Comparative Study of Anthropometric Measurement and Body Composition between Elite Handball and Basketball Players. Montenegrin Journal of Sports Science and Medicine, 3(2), 19-22.

Nikolaidis, P.T. \& Vassilios Karydis, N. (2011). Physique and body composition in soccer players across adolescence. Asian J. Sports Med., 2(2), 75-82.

Popovic, S. (2017). Local Geographical Differences in Adult Body Height in Montenegro. Montenegrin Journal of Sports Science and Medicine, 6(1), 81-87.

Popovic, S., Akpinar, S., Jaksic, D., Matic, R., \& Bjelica, D. (2013). Comparative Study of Anthropometric Measurement and Body Composition between Elite Soccer and Basketball Players. International Journal of Morphology, 31(2), 461-7.

Popovic, S., Bjelica, D., Jaksic, D., \& Hadzic, R. (2014). Comparative Study of Anthropometric Measurement and Body Composition between Elite Soccer and Volleyball Players. Int. J. Morphol., 32(1), 267-74.

Popovic, S., Bjelica, D., Petkovic, J., \& Muratovic, A. (2012). Comparative Study of Anthropometric Measurement and Body Composition between Elite Soccer and Handball Players. In 4th International Scientific Conference "Contemporary Kinesiology" (102-108). Split: Faculty of Kinesiology, University of Split.

Popovic, S., Masanovic, B., Molnar, S., \& Smajic, M. (2009). Determining Body Composition of Top Level Athletes. Teme, 33(4), 1534-1549.

Rexhepi, A.M., \& Brestovci, B. (2010). The differences in body volume and skinfold thickness between basketball and football players. International Journal of Morphology, 28(4), 1069-74. 
Saavedra, J.M., Porgeirsson, S., Kristjansdottir, H., Halldorsson, K., Gudmunds dottir, M.L., \& Einarsson, I.P. (2018). Comparison of training volumes in different elite sportspersons according to sex, age, and sport practised. Montenegrin Journal of Sports Science and Medicine, 7(2), 37-42. doi: $10.26773 / \mathrm{mjssm} .180906$

Sæther, S.A. (2017). Characteristics of professional and non-professional football players - an eight-year follow-up of three age cohorts. Montenegrin Journal of Sports Science and Medicine, 6(2), 13-8.

Stojanovic, M., Calleja-Gonzalez, J., Mikic, M., Madic, D., Drid, P., Vuckovic, I. \& Ostojic, S. (2016). Accuracy and Criterion-Related Validity of the 20-M Shuttle Run Test in Well-Trained Young Basketball Players. Montenegrin Journal of Sports Science and Medicine, 5(2), 5-10.

Taborsky, F. (2007). The Body Height and Top Team Handball Players.Vienna: EHF Web Periodical.
Vila Suarez, M.H., Ferragut, C., Alcaraz, P.E., Rodríguez Suarez, N., \& Cruz Martinez, M. (2008). Anthropometric and strength characteristics in junior handball players by playing positions. Archivos de Medicina del Deporte, 125(3), 167-177.

Vukasevic, V., Spaic, S., \& Masanovic, B. (2018). Comparative study of anthropometric measurement and body composition between the basketball player first and second league in Montenegro. Journal of Anthropology of Sport and Physical Education, 2(3), 61-65. doi: 10.26773/jaspe.180711

Vukotic, M., Corluka, M., Vasiljevic, I., \& Bubanja, M. (2018). Differences in the Morphological Characteristics and Body Composition of Handball Players WHC Levalea in Montenegro and WHC Grude in Bosnia and Herzegovina. Journal of Anthropopogy Sport and Physical Education, 2(2), $49-53$ 